\title{
STUDY OF INTRA ABDOMINAL PRESSURE IN ACUTE PANCREATITIS AND ITS CORRELATION WITH DISEASE SEVERITY
}

\begin{tabular}{ll}
\hline General Surgery & \\
Dr Nithin K B & Assistant Professor, Department Of Surgery, JSS Medical College And Hos \\
\hline $\begin{array}{l}\text { Dr Kaushalendra } \\
\text { Kumar* }\end{array}$ & $\begin{array}{c}\text { Department of General surgery,JSS Medical college and hospital, Mysuru. } \\
\text { *Corresponding Author }\end{array}$ \\
\hline
\end{tabular}

\section{Dr. B J Sharath} Chandra

Prof and HOD, Department of surgery, JSS Medical college and hospital, Mysuru.

\section{ABSTRACT}

INTRODUCTION: Acute pancreatitis is one of the commonly encountered surgical conditions in the emergency department. Prognostication is done by various biochemical assays and scoring systems. Intra abdominal pressure (IAP) measurement has strong potential use as a prognostication and interventional marker. In this study we aim to determine the association between the intra abdominal pressures and the severity, morbidity, mortality and the prognosis of the patient.

METHODS:This study is prospective observational study. 100 patients diagnosed with acute pancreatitis were observed from the day of admission and followed up to the day of discharge. Intra abdominal pressure to be measured by the intravesical method..

RESULTS :There was significant linear correlation between raised intra abdominal pressure (IAP) and duration of hospitalization. In groups of patients who suffered complications, IAP was noted to be significantly higher, compared to the group of patients with no complications. (p $<0.0001$ ) There was a significant correlation of the baseline IAP (IAP at admission) with the MCTSI (pearson correlation coefficient $=0.534$ ), APACHE II score (Pearson correlation coefficient $=0.511)$. IAP also showed positive linear correlation with ranson score $($ Pearson correlation coefficient $=0.383$ )

CONCLUSION: IAP measurement is cheap, easy, and minimally invasive modality. It can be easily measured in catheterized patients. It is faster and easier than the existing scoring modalities and can reliably predict hospital stay, complications, and the prognosis in acute pancreatitis.

\section{KEYWORDS}

\section{INTRODUCTION:}

Acute pancreatitis is an acute inflammatory process of the pancreas that affects peripancreatic tissues and at times remote organ systems ${ }^{[1]}$ It is one of the leading causes of hospitalization in the emergency department among gastroenterology disorders ${ }^{[2]}$. Disease spectrum ranges from mild disease to severe life threatening pancreatitis.

Diagnosis of pancreatitis is confirmed by two out of three criteria: ${ }^{[3]}$

1) pain abdomen,

2) biochemical markers, and/or

3) radiological diagnosis.

RANSON's criteria, IMRIE criteria, APACHE II are commonly used systems to predict the severity of the disease ${ }^{[3]}$ However not much emphasis is given to intra abdominal pressure. Raised intra abdominal pressure has been found to be strongly associated with cardiovascular, respiratory, and renal dysfunction in the critically ill ${ }^{[4]}$ historically, Several animal studies have been performed to explore the relationship between raised intra abdominal pressure and hemodynamic and respiratory alteration. ${ }^{[5,6]}$ In one study published in journal of surgical research, there was marked decline in cardiac output of dogs despite of normal arterial pressure and reduced vena caval flow showing reduced venous return $^{[[6]}$

Acute pancreatitis is one of the important causes of raised intra abdominal pressure. Some of the newer studies have established strong association between intra abdominal pressure and disease outcomes in acute pancreatitis. According to a study published in world journal of gastrointestinal pathophysiology, Intra abdominal hypertension can be expected in $17 \%$ of patient presenting with acute pancreatitis and in about $50 \%$ of patients with severe acute pancreatitis ${ }^{[7]}$

Current guidelines still not acknowledge the utility of IAP surveillance in severe acute pancreatitis (SAP) except Japanese society of hepatobiliary pancreatic surgery. ${ }^{[7]}$ There are now mounting evidences about the strong relationship between intra abdominal pressure and the severity of acute pancreatitis. ${ }^{[9]}$ However, clear cut guidelines are still to be framed.

\section{MATERIALS AND METHODS:}

a)Study design: prospective observational study

\section{b)Sampling techniques: purposive sampling.}

Study population includes:

1) patients visiting the JSS Hospital, Mysuru and diagnosed with acute pancreatitis, of age 12 years or more

Patients were managed according to the current guidelines for acute pancreatitis at JSS hospital. Their intra abdominal pressure was measured on the day of admission followed up to the day of discharge.

\section{EXCLUSION CRITERIA:}

1) Patients having supra pubic catheterization, or pre existing kidney disease, were excluded from the study

\section{METHOD:}

patients bladder be emptied and then $50 \mathrm{cc}$ normal saline to be pushed. Foleys outlet is clamped. It is then connected to the manometer. The level of pubic symphysis is taken as zero point. The pressure in the bladder is the direct reflection of intra abdominal pressure. ${ }^{[8]}$

\section{DATAANALYSIS:}

Summary statistics will be done by measuring mean SD and proportions.

Inferential statistics by using chi square tests, independent $\mathrm{t}$ test and repeated measure ANOVA.

All measurements to be done using SPSS 21.0

RESULTS:

Table 1: Age \& Sex Distribution Of Disease

\begin{tabular}{|c|c|c|c|c|c|c|c|}
\hline & \multicolumn{6}{|c|}{ SEX } \\
\hline & & \multicolumn{2}{|r|}{ Female } & \multicolumn{2}{|r|}{ Male } & \multicolumn{2}{|r|}{ Total } \\
\hline & & Count & Column N \% & Count & Column N \% & Count & Colur \\
\hline \multirow{6}{*}{$\begin{array}{c}\text { Age } \\
\text { group } \\
\text { yr }\end{array} \mid$} & $<30$ & 2 & $8.3 \%$ & 25 & $32.9 \%$ & 27 & $\frac{\mathrm{N} \%}{27.0 \%}$ \\
\hline & $31-40$ & 3 & $12.5 \%$ & 26 & $34.2 \%$ & 29 & $29.0 \%$ \\
\hline & $41-50$ & 5 & $20.8 \%$ & 17 & $22.4 \%$ & 22 & $22.0 \%$ \\
\hline & $51-60$ & 11 & $45.8 \%$ & 5 & $6.6 \%$ & 16 & $16.0 \%$ \\
\hline & $>61$ & 3 & $12.5 \%$ & 3 & $3.9 \%$ & 6 & $6.0 \%$ \\
\hline & Total & 24 & $100.0 \%$ & 76 & $100.0 \%$ & 100 & $100.0^{\circ}$ \\
\hline
\end{tabular}


Table 2: Correlation Between Iap, Mctsi, Apache Ii, And Ranson Score

\begin{tabular}{|c|c|c|c|c|c|}
\hline \multicolumn{6}{|c|}{ Correlations } \\
\hline & & $\begin{array}{c}\text { IAP } \\
\text { Baseline } \\
\text { mm of } \mathrm{Hg}\end{array}$ & RANSON & MCTSI & $\begin{array}{c}\text { APACHE } \\
\text { II }\end{array}$ \\
\hline \multirow{3}{*}{$\begin{array}{c}\text { IAP } \\
\text { Baseline } \\
\mathrm{mm} \text { of } \mathrm{Hg}\end{array}$} & $\begin{array}{c}\text { Pearson } \\
\text { Correlation }\end{array}$ & 1 & $.383^{* *}$ & $.534^{* * *}$ & $.511^{* *}$ \\
\hline & Sig. (2-tailed) & & .000 & .000 & .000 \\
\hline & $\mathrm{N}$ & 100 & 100 & 99 & 98 \\
\hline \multirow[t]{3}{*}{ RANSON } & $\begin{array}{c}\text { Pearson } \\
\text { Correlation }\end{array}$ & $.383^{*}$ & 1 & $.347^{\prime \prime}$ & $.273^{*}$ \\
\hline & Sig. (2-tailed) & .000 & & .000 & .007 \\
\hline & $\mathrm{N}$ & 100 & 100 & 99 & 98 \\
\hline \multirow[t]{3}{*}{ MCTSI } & $\begin{array}{c}\text { Pearson } \\
\text { Correlation }\end{array}$ & $.534^{* *}$ & $.347^{* *}$ & 1 & $.328^{* *}$ \\
\hline & Sig. (2-tailed) & .000 & .000 & & .001 \\
\hline & $\mathrm{N}$ & 99 & 99 & 99 & 98 \\
\hline \multirow[t]{3}{*}{ APACHE II } & $\begin{array}{c}\text { Pearson } \\
\text { Correlation }\end{array}$ & $.511^{* *}$ & $.273^{* *}$ & $.328^{* * *}$ & 1 \\
\hline & Sig. (2-tailed) & .000 & .007 & .001 & \\
\hline & $\mathrm{N}$ & 98 & 98 & 98 & 98 \\
\hline
\end{tabular}

Table 3: Iap Correlation With No Of Days Of Hospital Stay

\begin{tabular}{|c|c|c|c|}
\hline \multicolumn{2}{|c|}{} & $\begin{array}{c}\text { IAP } \\
\text { Baseline } \\
\text { mm of Hg }\end{array}$ & $\begin{array}{c}\text { Duration of stay } \\
\text { in days }\end{array}$ \\
\hline $\begin{array}{c}\text { IAP Baseline } \\
\text { mm of Hg }\end{array}$ & Pearson Correlation & 1 & $.394^{* *}$ \\
\cline { 2 - 4 } & Sig. (2-tailed) & & .000 \\
\cline { 2 - 4 } & $\mathrm{N}$ & 100 & 96 \\
\hline $\begin{array}{c}\text { Duration of } \\
\text { stay in days }\end{array}$ & Pearson Correlation & $.394^{* *}$ & 1 \\
\cline { 2 - 4 } & Sig. (2-tailed) & .000 & \\
\cline { 2 - 4 } & $\mathrm{N}$ & 96 & 96 \\
\hline
\end{tabular}

Table 4: Iap In Complication Vs Non Complication Group

\begin{tabular}{|c|c|c|c|c|c|}
\hline & \multicolumn{5}{|c|}{ Complications } \\
\hline & \multicolumn{2}{|c|}{ No } & \multicolumn{2}{|c|}{ Yes } & \\
\hline & Mean & SD & Mean & $\mathrm{SD}$ & \\
\hline IAP Baseline $\mathrm{mm}$ of $\mathrm{Hg}$ & 9.65 & 4.28 & 18.03 & 6.41 & $<0.0001$ \\
\hline IAP $24 \mathrm{hr} \mathrm{mm}$ of $\mathrm{Hg}$ & 9.25 & 4.42 & 17.69 & 6.41 & $<0.0001$ \\
\hline IAP $48 \mathrm{hr} \mathrm{mm}$ of $\mathrm{Hg}$ & 8.32 & 4.42 & 16.06 & 7.21 & $<0.0001$ \\
\hline IAP $72 \mathrm{hr} \mathrm{mm}$ of $\mathrm{Hg}$ & 7.06 & 3.80 & 13.50 & 6.46 & $<0.0001$ \\
\hline IAP $96 \mathrm{hr} \mathrm{mm}$ of $\mathrm{Hg}$ & 6.37 & 3.35 & 11.15 & 5.43 & $<0.0001$ \\
\hline $\mathrm{P}$ & \multicolumn{2}{|c|}{0.7} & \multicolumn{2}{|c|}{$<0.001$} & \\
\hline $\mathrm{P}$ & \multicolumn{2}{|c|}{$<0.0001$} & \multicolumn{2}{|c|}{$<0.0001$} & \\
\hline Effect size & \multicolumn{2}{|c|}{0.751} & \multicolumn{2}{|c|}{0.843} & \\
\hline
\end{tabular}

Table 5: Iap In Patients Expired Vs Recovered

\begin{tabular}{|c|c|c|c|c|c|}
\hline \multirow{2}{*}{} & \multicolumn{4}{|c|}{ DEATH } & \\
\cline { 2 - 6 } & \multicolumn{2}{|c|}{$\mathrm{N}$} & \multicolumn{2}{c|}{$\mathrm{Y}$} & \\
\cline { 2 - 6 } & Mean & SD & Mean & SD & $\mathrm{p}$ \\
\hline IAP Baseline $\mathrm{mm}$ of $\mathrm{Hg}$ & 11.23 & 5.27 & 24.70 & 2.58 & $<0.0001$ \\
\hline IAP $24 \mathrm{hr} \mathrm{mm} \mathrm{of} \mathrm{Hg}$ & 11.00 & 5.50 & 25.29 & 2.29 & $<0.0001$ \\
\hline IAP 48 hr mm of Hg & 9.82 & 5.40 & 25.83 & 2.32 & $<0.0001$ \\
\hline IAP 72 hr mm of Hg & 8.48 & 4.85 & 24.67 & 2.31 & $<0.0001$ \\
\hline IAP 96 hr mm of Hg & 7.50 & 4.01 & 23.50 & 2.12 & $<0.0001$ \\
\hline P & $<0.0001$ & \multicolumn{3}{|c|}{0.5} & \\
\hline Effect size & \multicolumn{2}{|c|}{0.77} & \multicolumn{5}{c|}{0.5} & \\
\hline
\end{tabular}

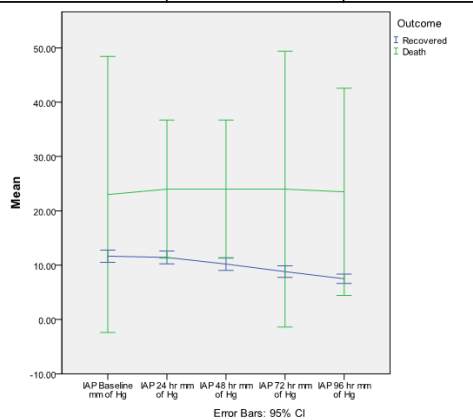

Figure1: mean IAP recorded along the course of disease
Table 6: detail statistics of the patients.

\begin{tabular}{|l|l|c|c|}
\hline \multicolumn{2}{|l}{} & Count & Column Total N \% \\
\hline \multirow{2}{*}{$\begin{array}{l}\text { Duration of stay in } \\
\text { days }\end{array}$} & $\begin{array}{l}\text { 7 days } \\
\text { ICU }\end{array}$ & 89 & $49.0 \%$ \\
\cline { 2 - 4 } & $8-14$ days & 46 & $46.0 \%$ \\
\cline { 2 - 4 } & No days & 5 & $5.0 \%$ \\
\cline { 2 - 4 } & Yes & 62 & $62.0 \%$ \\
\hline \multirow{3}{*}{ ATLANTA } & MILD & 48 & $38.0 \%$ \\
\cline { 2 - 4 } & MODERATAE & 1 & $44.0 \%$ \\
\cline { 2 - 4 } & MODERATE & 37 & $1.0 \%$ \\
\cline { 2 - 4 } & SEVERE & 18 & $37.0 \%$ \\
\hline Complications & 00 & 65 & $65.0 \%$ \\
\cline { 2 - 4 } & 1.00 & 35 & $35.0 \%$ \\
\hline \multirow{3}{*}{ PROGNOSIS } & $\mathrm{F}$ & 51 & $51.0 \%$ \\
\cline { 2 - 4 } & $\mathrm{G}$ & 27 & $27.0 \%$ \\
\cline { 2 - 4 } & $\mathrm{P}$ & 22 & $22.0 \%$ \\
\hline \multirow{2}{*}{ DEATH } & $\mathrm{N}$ & 90 & $90.0 \%$ \\
\cline { 2 - 4 } & $\mathrm{Y}$ & 10 & $10.0 \%$ \\
\hline
\end{tabular}

1) Patient with hospital stay $<7$ days had mean amylase 791.38 , and mean serum lipase 1560.1. Mean IAP on admission for the same group was $9.53 \mathrm{~mm}$ of hg. Patients with hospital stay $8-14$ days had mean serum amylase and serum lipase 800.45 and 1360.34 respectively. Mean IAP on admission for the same was $13.78 \mathrm{~mm}$ of hg. Patient with hospital stay $>14$ days had mean amylase as 683.00 and mean serum lipase 1770.6. Mean IAP on admission for the same group was $19.40 \mathrm{~mm}$ of hg.

2) Baseline IAP of patients showed positive correlation with hospital stay of the patients. (pearson correlation coefficient $=0.394$ ) Correlation is significant at the 0.01 level.

3) In patients who suffered one or more complications, mean baseline IAP was relatively higher (mean IAP $=18.03 \mathrm{~mm} \mathrm{hg}$ ) when compared to the group of patients who had no complications. (mean IAP $=9.65 \mathrm{~mm} \mathrm{hg}$ ). P value for this correlation was significant. $(\mathrm{p}<0.0001)($ TABLE 16)

4) Mean IAP at 24 hours and 48 hours for patients suffering any complications were $17.69 \mathrm{~mm} \mathrm{hg}$ and $16.06 \mathrm{~mm} \mathrm{hg}$ respectively. Whereas the mean IAP for the patients who did not suffer any complications were $9.25 \mathrm{~mm} \mathrm{hg}$ and $8.32 \mathrm{~mm} \mathrm{hg}$ at 24 and 48 hours respectively. P value for this correlation was significant. ( $\mathrm{p}<$ 0.0001). Effect size for this correlation was 0.843 for patients with complication group and 0.751 in patients with no complications group. (TABLE 16)

5) In the patients who expired of the disease, the mean IAP at admission was $24.70 \mathrm{~mm}$ of $\mathrm{hg}, \mathrm{SD}=2.58$; whereas in the patients who recovered from the disease, the mean IAP was $11.23 \mathrm{~mm}$ of hg with $\mathrm{SD}=5.27$. IAP for the expired patients at 24 hours and 48 hours continued to be high with mean IAP being 25.29; $\mathrm{SD}=2.29$ and $25.83 ; \mathrm{SD}=2.32 ; \mathrm{mm}$ of hg respectively. However patients who recovered from the disease, had relatively lower mean IAP of $11.00 \mathrm{~mm} \mathrm{hg} \mathrm{SD}=5.50$ and $9.82 \mathrm{~mm} \mathrm{hg} \mathrm{SD}=5.40$. Effect size for the measured variables was 0.77 for the recovered group and 0.5 for the expired group.

\section{DISCUSSION:}

This study was undertaken at jss hospital with the purpose to relate the intra abdominal pressure with disease severity in cases of acute pancreatitis. Out of the 100 patient that were observed, acute pancreatitis appears to be more common in males than females, with 76 percent cases being males.

Alcohol was the most common cause, followed by gall stones. Ethanol induced pancreatitis constituted $54 \%$ of the total pancreatitis cases.

Majority of the patients belonged to the age group 31 years -50 years. Most of the cases encountered in this study were mild to moderate, with severe cases being 18 out of 100.40 out of 100 cases suffered no complication, while 60 patients suffered some complication.

When assessed by the number of days of hospital stay. 45 patients were in the hospital for less than 7 days and 46 were in hospital for $7-14$ days. IAP at admission (baseline IAP) was significantly higher in patient with longer hospital stay. The mean baseline IAP in patients having hospital stay $>14$ days was 19.40 with SD 3. 85. In the group of patients with hospital stay between 7 to 14 days, the baseline IAP was $13.78 \mathrm{~mm} \mathrm{hg}$, with SD 4.42. And for the group with hospital stay less than 7 days, the mean baseline IAP was 9.53, with SD of 6.60. as we try to understand the statistical analysis, we can imply that IAP was lesser 
for the patients who stayed less in the hospital, and it decreased rapidly to attain normal values. Accordingly patients improved and were discharged. However the patients with higher IAP values on admission had relatively severe disease and needed longer hospital stay. The lower SD values in such cases depicts that it took longer time for IAP to reduce and attain near normal values.

When correlated together, IAP and the duration of hospital stay show significant linear correlation with pearson correlation coefficient value $=0.394($ Table 5,17$)$

Out of the 100 patients 38 patients needed ICU care, while 68 patient were managed in wards. Baseline IAP values were found to be higher in patients who suffered some complication. Mean IAP was 18.03 while in patients who had no complication mean baseline IAP was 9.65 $\mathrm{mm} \mathrm{hg}$. This value was significant $(\mathrm{p}<0.0001)$. hence IAP can also be used as a predictor of complications.

Similarly, for the patients who expired, the baseline IAP was high compared to those who recovered from the disease. Mean IAP on admission in patients who expired was $24.70 \mathrm{~mm} \mathrm{Hg}$ with SD 2.58 . Mean IAP on admission for patients who recovered was 11.23 with SD of 5.27. as can be understood from the smaller SD, IAP for expired patients remained high during the course of the treatment, and showed minimal decrease overtime. effect size was found to be 0.5 for expired patients, compared to those who recovered (effect size 0.77). hence baseline IAP shows good potential in predicting the mortality.

When compared to the prognosis of the patients, baseline IAP in patients who had poor prognosis was higher, mean IAP $=20.95 \mathrm{~mm} \mathrm{hg}$. In patients with guarded prognosis mean baseline IAP was $12.56 \mathrm{~mm}$ hg. However mean baseline IAP was $8.98 \mathrm{~mm}$ hg in fair prognosis group. The correlations were significant with $\mathrm{p}=<0.0001$

IAP showed linear correlation with the ranson score at admission, (pearson correlation 0.383).

When compared with APACHE II score, IAP shows linear correlation. Pearson correlation coefficient complex was 0.511 , showing moderate correlation. Similarly moderate linear correlation is seen with the RANSON'S score at 48 hours (pearson correlation coefficient $0.563)$. IAP also shows significant correlation with atlanta classification of acute pancreatitis.

\section{CONCLUSION:}

Raised IAP is seen in about 60 percent of the patients with acute pancreatitis. As seen in this study, significantly high baseline IAP values are noted in severe cases, with persistently high IAP values associated with death of the patient. IAP values show positive correlation with disease severity, complications and hospitals stay. IAP measurement is cheap, fast, safe, and gives a reliable picture of patients condition. IAP can well be used to predict the disease severity and disease outcome. In selected cases, it can also be used as an indicator for surgical intervention. IAP surveillance must be a part of management protocol for acute pancreatitis.

\section{REFERENCES:}

. Pandol, S. J., Saluja, A. K., Imrie, C. W., \& Banks, P. A. (2007). Acute pancreatitis: bench to the bedside. Gastroenterology, 133(3), 1056-e1

2. Peery, A. F., Dellon, E. S., Lund, J., Crockett, S. D., McGowan, C. E., Bulsiewicz, W. J., \& Ringel, Y. (2012). Burden of gastrointestinal disease in the United States: 2012 update. Gastroenterologv, 143(5), 1179-1187.

3. Walsh, M. K. (2008). Diagnosis, prognosis, and treatment of acute pancreatitis. American family physician, $77(5), 594$.

4. Cheatham, M. L. \& Malbrain, M. L. N. G. (2007). Cardiovascular implications of abdominal compartment syndrome. Acta Clinica Belgica, 62(sup1), 98-112.

. Richardson, J. D., \& Trinkle, J. K. (1976). Hemodynamic and respiratory alterations with increased intra-abdominal pressure. Journal of surgical research, 20(5), 401-404.

6. Harman, P. K., Kron, I. L., McLACHLAN, H. D., Freedlender, A. E., \& Nolan, S. P. (1982). Elevated intra-abdominal pressure and renal function. Annals of surgery, 196(5), 594.

7. Jaipuria, J., Bhandari, V., Chawla, A. S., \& Singh, M. (2016). Intra-abdominal pressure: Time ripe to revise management guidelines of acute pancreatitis?. World Journal of Time ripe to revise management guidelines 0

8. Fusco, M. A., Martin, R. S., \& Chang, M. C. (2001). Estimation of intra-abdominal Fusco, M. A., Martin, R. S., \& Chang, M. C. (2001). Estimation of intra-abdominal
pressure by bladder pressure measurement: validity and methodology. Journal of Trauma and Acute Care Surgery, 50(2), 297-302.

9. De Waele, J. J., Hoste, E., Blot, S. I., Decruyenaere, J., \& Colardyn, F. (2005). Intraabdominal hypertension in patients with severe acute pancreatitis. Critical Care, 9(4), 16 . 